\title{
A CRIANÇA NEGRA E A REPRESENTATIVIDADE RACIAL NA ESCOLA
}

\author{
CAROLINA ZOLIN CARNEIRO* \\ MARIA JOSÉ DE OLIVEIRA RUSSO**
}

\begin{abstract}
RESUMO
O presente trabalho discorre sobre a falta de representatividade racial no ambiente escolar. A presença da diversidade no universo lúdico das crianças é de suma importância, pois contribui para que todas possam lidar desde cedo com aquilo que há de diferente, tanto em si quanto no outro, respeitando-se mutuamente, convivendo com as diferenças e aceitando os diversos tipos físicos. O Brasil é o país que tem a maior população de origem africana fora da África, porém essa pluralidade étnica não é representada nos brinquedos e muitas vezes também registra sua ausência dentro das escolas. Esse problema nos leva à necessidade de refletir sobre a importância de elementos afirmativos no convívio social das crianças, promovendo um debate acerca da presença da representatividade nos espaços escolares para o desenvolvimento construtivo e significativo. Dessa maneira, para fazer essa discussão, contamos com a contribuição de autores como Frantz Fanon, Nilma Lino Gomes, Guacira Lopes, Kabengele Munanga, Fúlvia Rosemberg, entre outros. Vale ressaltar que
\end{abstract}

* Professora da rede privada do município de São Paulo. Aluna concluinte do curso de Pedagogia da Universidade Metodista de São Paulo em 2019. Autora do trabalho de Conclusão de Curso intitulado "A representatividade racial nos brinquedos: reflexões necessárias na Educação Infantil”. Defendido em 28/11/2019, junto à Universidade Metodista de São Paulo.

** Doutora em Educação. Coordenadora e docente do curso de Pedagogia presencial da Universidade Metodista de São Paulo. Orientadora do TCC que deu origem a este artigo. 
é fundamental buscar e conferir diferentes expressões de vida, de arte e de cultura no processo de socialização da criança negra na primeira infância, levando isso para dentro das escolas, que é o principal lugar de direito de todas as raças.

Palavras-chave: Representatividade Racial. Crianças. Contexto escolar.

\begin{abstract}
The current article discourses about the lack of racial representativity in the scholar ambient,. The diversity presence in children world is of major importance, because it contributes to kids to deal, since early years, with what is different in themselves and in others, respecting mutually and living with the differences, accepting the diverse physical types. Brazil is the country with the biggest population of african origins outside Africa, but this ethnic plurality is not represented in toys and is frequently absent inside schools. This problem lead us to the necessity of thinking about the affirmative elements importance in children social living, promoting a debate about representativity presence in scholar espaces to the development constructive and meaningful ways. Thus, to do this discussion, we count with the contribution of authors such as Frantz Fanon, Nilma Lino Gomes, Guacira Lopes, Kabengele Munanga, Fúlvia Rosemberg and others. It's fundamental to seek and check different life, art and culture expressions in black child socialization process since the early childhood, bringing it to the inside of the schools, which is the main place guaranteed by law for all races.
\end{abstract}

Keywords: Racial Representativity. Children. School contextt.

\title{
INTRODUÇÃO
}

A presença de diferentes etnias no ambiente escolar amplia o reconhecimento da identidade, da autoestima, da autovalorização e do "empoderamento" infantil para as crianças, que dificilmente se veem representadas nos recursos existentes em 
seu universo. Além disso, os elementos que contemplam a diversidade étnica proporcionam a identificação positiva e permitem a construção dessa autoestima, para que as crianças tenham um bom relacionamento tanto com a sua autoimagem quanto com a imagem do outro.

Por meio do universo lúdico e da brincadeira, é possível que as crianças ampliem a sua percepção de mundo, bem como aprendam sobre o funcionamento da vida cotidiana e, a partir disso, construam uma série de "verdades" que lhe acompanharão pelo resto da vida.

Nesse âmbito, nota-se a necessidade de um aprofundamento sobre um tema que ainda requer muitos debates: a falta de representatividade racial dentro das escolas.

Essa representatividade, que pode vir agregada ao brinquedo, pode ser decisiva na construção de uma imagem ou autoimagem (para a criança que se reconhece no brinquedo) positiva. É preciso que estes objetos estimulem o conhecimento de si e do outro e ajudem a criança a enxergar a si e ao colega, sendo possível que o brinquedo faça refletir a criança que brinca com ele. Essa diversidade é extremamente importante para que todas as crianças possam lidar com o diferente no outro, respeitando-se mutuamente e convivendo com as diferenças, aceitando os diversos tipos físicos.

Segundo dados do IBGE de 2018, negros e pardos representam 54,7\% da população brasileira. Porém, ainda há pouca representatividade desse grupo no que diz respeito à esfera comercial. Nos últimos anos, apesar do crescimento de marcas de roupas, cosméticos e publicidade voltadas para o público afro, alguns setores ainda estão distantes dessa revolução. Como exemplo, temos o mercado de brinquedos, em que apenas $3 \%$ dos bonecos e bonecas vendidas em lojas do país são negras (de acordo com o estudo realizado pela ONG Avante em 2016). Desse contexto, emerge um questionamento: diante da grande pluralidade da população brasileira, por que os brinquedos não retratam essa diversidade? 
Uma possibilidade de resposta para estas questões talvez esteja ligada ao fato de que os brinquedos e, principalmente, os(as) bonecos(as), são construídos(as) sob um padrão: todas são brancas, loiras e possuem olhos claros. Desse modo, a segregação tanto social quanto racial é impregnada nas crianças desde muito cedo. A supremacia branca, presente nas prateleiras das lojas e muitas vezes também na esfera escolar, identifica uma hegemonia utilizada para inculcar conceitos, valores e símbolos, tendo como objetivo a manutenção do status quo.

Tal fato revela a interiorização de um processo histórico imposto ideologicamente, ou seja, trata-se da ilustração dos efeitos psicossociais do racismo, que prega que os negros são naturalmente "feios" ou "inferiores". Demonstra ainda que esse discurso de imposição, de dominação política e até mesmo de humilhação social histórica é tão eficiente que as próprias pessoas negras o reproduzem sem perceber, tornando o racismo ainda maior.

Este tema aponta para a necessidade de levantar o debate sobre sua importância e o aprofundamento das questões étnico-raciais dentro do cenário educacional. Os brinquedos (muito presentes nesse contexto) fazem parte do universo lúdico das crianças e são, em geral, os primeiros objetos para os quais as crianças dão cuidado e carinho. Nesse sentido, se o brinquedo não se parece em nada com elas, se as crianças não se veem nas suas bonecas ou bonecos, por exemplo, a sua autoestima, desde a primeira idade, pode ficar comprometida.

Assim, a falta de representatividade pode ser um problema, uma vez que o processo de autoidentificação é fundamental para a criança. Além disso, a presença da diversidade no cotidiano escolar torna-se importante para que todas as crianças possam conviver com as diferenças e aceitar os vários tipos físicos. Espera-se com esta discussão contribuir com um olhar referente à importância da representatividade e do empoderamento infantil, atuando diretamente na construção de autoestima das 
crianças, principalmente das negras, de modo que elas se sintam pertencentes ao seu contexto social de forma segura e completa.

Em face, portanto, da valorização da diversidade e da inclusão como temas que se encontram em debates educacionais não só no Brasil, mas também no mundo, o processo de socialização da criança negra na primeira infância, deve ser mote de muitas pesquisas, sobretudo porque a falta de representatividade étnico-racial nos brinquedos ainda está presente no ambiente escolar. Assim, faz-se necessária uma conscientização crítica para que se produza uma cultura de valorização das diferentes etnias. Pelo viés da educação, com seu caráter transformador e libertador, é preciso ajudar a sociedade a olhar de forma diferente para as nossas crianças, valorizando-as e proporcionando, de fato, um sentimento de respeito à identidade das crianças negras.

Sob essa ótica, este artigo busca levantar as contribuições possíveis da educação na desconstrução de estereótipos, do mesmo modo que ressaltamos a importância das africanidades na criação de possibilidades de intervenção no processo de formação da identidade no período da educação infantil, visando que narrativas dominantes sobre o "ser negro" possam ser construídas dentro do ambiente educativo de uma forma resistente e positiva.

\section{AS RELAÇÕES ÉTNICO-RACIAIS E A CULTURA NEGRA}

As relações étnico-raciais são formadas ao longo da história por meio da construção de imagens e representações sociais. Essas representações pertencem a todos os grupos sociais e circundam no meio social produzindo sentidos e consequências (FERNANDES; SOUZA, 2016). No entanto, a esse respeito, Guacira Lopes Louro assinala que algumas representações ganham maior visibilidade e passam a ser consideradas como expressão da realidade social. Na sociedade brasileira não é diferente e, assim como em outras, as representações que prevalecem 
são construídas a partir de narrativas hegemônicas, representando um grupo social em detrimento do outro. (LOURO, 2009).

Essas representações foram construídas sob o ponto de vista europeu, que estabeleceu os conceitos do que é "normalidade", determinando como norma padrão a imagem do homem, branco, heterossexual e cristão. Os indivíduos que não correspondem a esse padrão são vistos como digressivos e são automaticamente e, por que não dizer, lamentavelmente, excluídos dos diversos espaços sociais.

A abjeção decorre da criação de "marcadores sociais" que, formulados a partir de teorias biológicas errôneas, fazem das marcas corporais elementos através dos quais se pode homogeneizar os sujeitos e naturalizar identidades. A reificação de que era objeto o africano escravizado e seus descendentes foi metamorfoseada, no fim do século XIX e início do XX, em teorias racistas que tiveram por base aquilo que na época era considerado biologia científica. A ideia de raça dos sujeitos passou a ser deduzida por meio dessas marcas corporais, dedução que resultou na essencialização das identidades. (FERNANDES; SOUZA. 2016, p. 105, grifos das autoras).

Nesse sentido, as autoras explicam que estas formulações correspondem a uma visão equivocada sobre o corpo, uma vez que a identidade não pode ser considerada como decorrente das evidências corporais.

Isso significa que mesmo nas ideologias em que o racismo se faz presente, existem variantes, ou seja, as definições de negro ou branco no Brasil não acontecem da mesma forma que nos Estados Unidos, por exemplo. No entanto, para as ideologias racistas "o corpo é visto como a corte de julgamento final sobre o que somos ou que podemos nos tornar" (LOURO, 2009, p. 8)

Apesar disso, Louro destaca que o corpo não tem uma concepção estática, uma vez que ele é significado e alterado 
constantemente pela cultura. Avtar Brah, professor de sociologia e especialista em questões de raça, gênero e identidade étnica, compara esses marcadores sociais a diferenças, evidenciando que as marcas produtoras de diferenciação social é que estabelecem lugares distintos para os sujeitos dentro de uma estrutura social. (BRAH, 2006)

$\mathrm{Na}$ mesma vertente, o autor Stuart Hall elucida que esses "marcadores" caracterizam "unidades" que resultam de um processo de naturalização e fechamento a partir do contraste entre os termos marcados como, por exemplo, "mulher" e "negro" e termos não marcados como "homem" e "branco". Para este autor, "a identidade só pode ser entendida como algo que é construído por meio da diferença”. (HALL, 2003, p. 346, grifos de HALL)

Os marcadores sociais funcionam, portanto, como um determinador de limites por meio dos quais os sujeitos constroem a sua identidade, pesando sobre a sua produção. Diante disso, para compreendermos o processo de construção identitária é importante identificar que "não nos constituem inteiramente, somos sempre diferentes e estamos sempre negociando diferentes tipos de diferenças - de gênero, sexualidade e de classe" (HALL, 2003, p. 346).

Assim, identidade é algo que se dá em constante processo e que se manifesta por meio da consciência da diferença e do seu contraste com o outro. Ou seja, "o sujeito se constrói a partir de marcas diferenciais provindas dos outros" (FERNANDES; SOUZA apud NASCIMENTO, 2016, p.106). Desse modo, podemos entender que a identidade é sempre construída a partir de um processo de interação e de diálogo que estabelecemos uns com os outros.

Por este ângulo, o racismo torna-se um grande obstáculo entre os diferentes grupos que compõem a sociedade brasileira, uma vez que cria fronteiras simbólicas consistentes, contrapondo a identidade do que é "ser negro" para a identidade do que é 
"ser branco", atribuindo aspectos negativos para o primeiro e positivos para o segundo. O racismo é, portanto, um modo de negação ou de disparidade perante a população negra, impregnando-as em estereótipos e marcando-as por uma essência de inferioridade, negando as suas diferenças, cultura e valor.

Neste contexto, destacamos a importante contribuição de Frantz Fanon, que, em sua obra "Pele negra, máscaras brancas", deixa claro que o negro tem a sua cor de pele utilizada como principal marca de estigmatização. $\mathrm{O}$ autor chama esse processo de "esquema epidérmico" do sistema colonial, fazendo alusão a uma estrutura de discursos culturais, políticos e históricos para estigmatizar a figura da pessoa negra:

O mundo branco, o único honesto, rejeitava minha participação. De um homem exige-se uma conduta de homem; de mim, uma conduta de homem negro - ou pelo menos uma conduta de preto. Eu acenava para o mundo e o mundo amputava meu entusiasmo. Exigiam que eu me confinasse, que encolhesse. (FANON, 2008, p. 107).

O autor também ressalta que algumas sociedades edificam discursos e significados que visam reduzir o negro a uma cor, levando-o a elaborar um esquema corporal, histórico e social nos moldes fornecidos pelo outro - o branco - e não por ele próprio.

Em consonância com estas concepções, Izilidinha B. Nogueira traz elementos que nos permitem observar o processo de estigmatização a que se encontram submetidos muitos indivíduos negros. Para a autora, a rede de significações a respeito do corpo negro foi elaborada culturalmente e está relacionada à necessidade de estipular um modelo daquilo que é desejável. Foi a partir desse modelo que se construiu a imagem do inaceitável perante o "corpo negro", concomitantemente ao passo em que se investiu, em representações positivas do "corpo branco", tidos como puros, belos e sagrados. Assim, o "corpo negro" 
é assinalado como a sua marca de identidade, desconsiderando sua memória histórica, a sua diversidade e o seu contexto tanto social quanto cultural. (NOGUEIRA, 1998).

De acordo com Goffman (apud FERNANDES; SOUZA, 2016), a categorização do negro é uma tentativa de aprisioná-lo a uma alteridade forjada, a um lugar social que lhe impõe características de desacreditado, fazendo com que a "marca" que a ele é imposta na relação social o impeça de perceber e de ser percebido por seus atributos.

Nota-se que a identidade pessoal é subsumida à identidade social. O que faz com que o sujeito negro seja compreendido de acordo com a essencialização de seu grupo étnico-racial. Nas palavras de Edith Piza: “[...] o lugar do negro é o lugar de seu grupo como um todo e do branco é o de sua individualidade. Um negro representa todos os negros. O branco é uma unidade representativa apenas de si mesmo", ${ }^{1}$ (FERNANDES; SOUZA. 2016, p. 108).

O professor e antropólogo, Kabengele Munanga, descreve que para os negros os estereótipos se configuram com uma identidade coletivamente atribuída, como resultado da seleção dos atributos (pertencentes a todos os campos do seu complexo cultural) selecionados pelo grupo opositor. Outra dimensão que também faz parte do processo de construção da identidade é a de autoatribuição ou autodefinição, que acontece quando o próprio grupo seleciona os seus atributos para se autodefinir.

Neste viés, a identidade estereotipada atrelada ao negro refere-se a algo espúrio socialmente com a intenção de inferiorizá-lo. No que diz respeito à sociedade brasileira, essa identidade

PIZA, Edith. Porta de vidro: entrada da branquitude. In: CARONE, Iray; BENTO, Maria. A. S. (orgs.). Psicologia social do racismo: estudos sobre branquitude e branqueamento no Brasil. Petrópolis: Vozes, 2002, p. 72. 
foi construída historicamente desde o período colonial, pautada na inferiorização das diferenças do corpo escravizado.

Nilma Lino Gomes destaca que essa inferiorização do corpo negro foi um mecanismo utilizado pelo regime escravista para tentar explicar a coisificação do homem negro, "abafando”, assim, as reais intenções econômicas e políticas. A autora também evidencia que a comparação entre as características do corpo negro, como a cor, o cabelo crespo, o nariz etc. e as características do corpo branco europeu serviram como base de argumentação para a edificação de um padrão de beleza que persegue o grupo étnico-racial desde muito cedo até os dias de hoje. (GOMES, 2003). Ou seja, o corpo passa a ser uma expressão de identidade e as diferenças são usadas para embasar o processo de hierarquização social. Assim, a identidade atribuída à pessoa negra faz parte de uma construção social e que, embora não seja verdade, produz efeitos nocivos sobre ela.

Tanto a dimensão da identidade atribuída quanto a de autoatribuição são construídas coletivamente e se transformam de acordo com o contexto social, cultural e político no qual está inserido. Porém, a identidade atribuída é única e está atrelada à essência, ou seja, as relações de poder circundam sobre a essência do que é ser negro. Já a identidade de autoatribuição - identidade negra - não se trata de uma essência e sim, de um posicionamento. Ainda assim, esse percurso histórico de construção e reconstrução histórica mantém relação com as diferenças que possibilitam aos grupos estabelecer suas referências de pertencimento e reconhecimento positivo. (FERNANDES; SOUZA, 2016).

Lia Vainer Schucman aponta que ser negro não é uma entidade fixa e mutável, porém “[...] ser negro no Brasil é uma condição objetiva em que, a partir de um estado primeiro, definido pela cor de pele e pelo passado, o negro é constantemente remetido a si mesmo pelos outros". (SCHUCMAN, 2012, p. 40). Por isso, podemos dizer que no campo individual 
de construção da identidade, o negro, na sociedade racista, fica confinado perante as condições objetivas e de um imaginário comum alicerçado em caracterizações e significações negativas sobre o seu próprio grupo étnico-racial.

Ana Célia Silva, na mesma vertente, destaca que o preconceito, os estereótipos e o julgamento são objetos internalizados na consciência através da ideologia na resistência das diferenças utilizadas para a construção de uma percepção social do negro que é, simultaneamente, objetiva e subjetiva. Por outro lado, a autora afirma que essa representação não é fechada e pode ser modificada por meio de elementos advindos ao longo do processo; e assinala que a representação social é ativa e constantemente reconstrói os dados vindos do exterior:

[...] transformar as representações sociais significa transformar os processos de formação de conduta em relação ao outro representado, bem como as relações com esse outro, porque na medida em que essas representações não apresentarem objetos de recalque e inferiorização desse outro, a percepção inicial e o conceito resultando dessa percepção, em nossa consciência, terá grande aproximação com o real. (SILVA, 2011, p. 29).

No que diz respeito à relação entre racismo e subjetividade, Fanon (2008) chama a atenção para um ponto importante. Segundo o autor, a subjetividade do negro é marcada por uma neurose tão intensa, que é capaz de gerar uma alienação da sua condição de sujeito negro, levando-o até a pensar sob a ótica da pessoa branca. Vale lembrar que essa situação não é resultado de algo intrínseco ao negro, mas sim como uma consequência histórica de um complexo processo de construção identitária em que se estabelece essa referência de se pensar socialmente no contexto dos brancos. 
[...] o negro vive uma ambiguidade extraordinariamente neurótica. Com vinte anos, isto é, no momento em que o inconsciente coletivo é mais ou menos perdido, ou pelo menos difícil de ser mantido no nível consciente, o antilhano percebe que vive no erro. Por quê? Apenas porque, e isso é muito importante, o antilhano se reconhece como preto, mas, por uma derrapagem ética, percebeu (inconsciente coletivo) que era preto apenas na medida em que era ruim, indolente, malvado, instintivo. Tudo o que se opunha a esse modo de ser preto, era branco. Deve-se ver nisso a origem da negrofobia do antilhano. No inconsciente coletivo, negro=feio, pecado, trevas, imoral. Dito de outra maneira: preto é aquele que é imoral. Se, na minha vida, me comporto como um homem moral, não sou preto. Daí se origina o habito de dizer na Martinica, do branco que não presta, que ele tem uma alma de preto. A cor não é nada, nem mesmo a vejo, só reconheço uma coisa, a pureza da minha consciência e a brancura da minha alma. (FANON, 2008, p. 162-163).

$\mathrm{Na}$ sociedade brasileira, essa disparidade é especialmente marcada pelo caráter típico do racismo no Brasil, fortemente marcado pelo ideal do branqueamento e pelo mito da democracia racial ainda existente. "A dificuldade de se pensar a questão racial está ligada ao processo de desmemorização das vicissitudes históricas da diáspora africana, principalmente daquelas relacionadas à construção da identidade negra no Brasil". (FERNANDES; SOUZA, 2016. p. 111).

No Brasil, de acordo com a análise de Oracy Nogueira, a pele clara acrescida de outros traços corporais possibilita a uma pessoa com ascendência africana se intitular com branca. Concomitantemente, a mestiçagem foi, depois de muito tempo, reconhecida e depois levada a um patamar de mito nacional. (NOGUEIRA, 2007). 
Sobre isso, Roberto DaMatta denomina de "triângulo das raças" o mito que levou intelectuais e homens comuns a perceberem a sociedade brasileira como sendo unificada pelos laços inter-raciais. Nesse contexto, o branco se encontra no ângulo superior do triângulo. Já os negros e os índios, sempre abaixo e submetidos, nos ângulos da base. Esse mito faz com que olhemos tanto no plano político quanto no econômico de forma homogênea para uma sociedade extremamente desigual, explícita e estrategicamente hierarquizada no quesito racial. (DAMAT'TA, 1983).

Relacionado a isso, as contribuições de Fernandes e Souza (2016) apontam que:

A fábula da democracia racial dissimula tensões raciais e cria a ilusão de inclusão, silenciando vozes que denunciam a violência real e simbólica, construindo, de muitas formas, tanto lugares de privilégio quanto de exclusão e discriminação. As estigmatizações e humilhações sociais cotidianas, explícitas ou implícitas, sutis ou veladas, levam muitas vezes à formação de uma identidade negra ambígua e fragmentada. O ideal do branqueamento conduz alguns negros ao paradoxo instalado em sua subjetividade - a desejar tudo aquilo que representa a sua negação, ou seja, a brancura. (p. 112).

Nesse sentido, Nogueira (1998) faz uma análise do processo de alienação dos negros brasileiros por meio do seu próprio corpo. Dessa forma, ela coloca que muitas vezes os negros são levados ao ódio com relação ao seu próprio corpo e à sua condição, seguindo por um caminho de autodestruição que, geralmente, começa na tentativa de apagar suas marcas físicas (branqueamento físico, mutilações e etc.) e psíquicas (negação da sua condição física de pessoa negra). Assim, iniciam uma busca por uma falsa identidade, ou seja, não representam àquilo 
que são verdadeiramente. Isto tem a ver com uma "identidade rotulada que se estabelece mediante a anulação da capacidade autônoma de identificação, produzindo uma internalização do estigma [...] imposto socialmente”. (MELLUCI, 2004, p. 51). Esse estigma impede o negro de construir e desenvolver um sentimento e pertencimento racial ao mesmo tempo em que o atrapalha na construção da sua autoestima fundamentada em uma identidade racial positiva.

Portanto, é necessário ressaltar que a construção do "ser negro" passa pelo modo como o seu grupo étnico-racial foi (e ainda é) representado socialmente, uma vez que as representações são fundamentais para o processo de construção - e também de reconstrução - das identidades individuais ou coletivas. Assim, as representações sociais podem ser modificadas, transformando o modo como os sujeitos se percebem e se consideram e é nesse ponto que entra o papel fundamental da educação.

\section{A IMPORTÂNCIA DA IDENTIDADE NEGRA NAS ESCOLAS}

Sob o ponto de vista educacional, o Movimento Negro brasileiro vem exercendo um importante trabalho para que a representação social do negro seja reavaliada em todos os seus contextos sociais, principalmente na escola. Dessa forma, a escola deve ser vista como principal espaço para desconstrução de conceitos e termos fixados construídos historicamente, por se tratar de um ambiente privilegiado que proporciona uma intensa troca de culturas e de vivências entre os sujeitos vindos dos mais diversos grupos étnico-raciais. Assim, a escola é o lugar onde devem ser trabalhados, além dos saberes e conteúdos escolares, valores e crenças relacionados à raça, gênero e classe social. Sobre isso, Gomes (2003) comenta:

A escola, enquanto instituição social responsável pela organização, transmissão e socialização do conhecimento 
e da cultura, revela-se como um dos espaços em que as representações negativas sobre o negro são difundidas. E por isso mesmo ela também é um importante local onde estas podem ser superadas. (p. 77).

Dessa forma, o debate educacional torna-se ainda mais relevante, uma vez que a escola é um dos principais (se não o principal) ambiente para enfrentamento e combate ao racismo, bem como às atitudes discriminativas e preconceituosas. "O processo de reação à violência racial ganha expressão no Movimento Negro brasileiro, em luta histórica pela desconstrução da visão estereotipada a respeito da história e cultura africana e afro-brasileira”. (JESUS, 1997, p. 42). Marilene Paré, em seu estudo de 2000, sobre autoimagem e autoestima na criança negra, assinala uma diferença: a criança branca constrói sentimento de autoestima e autoconfiança, enquanto que na criança negra desponta um sentimento de baixa autoestima e a vergonha de ser negro.

Por isso, a resistência das raízes culturais africanas na escola torna-se um obstáculo para as crianças negras, não só na inserção de uma história coletiva, mas também no trabalho com elementos de identificação positivos. Torna-se um problema, então, à medida que suas origens étnicas não são representadas ou aparecem de maneira folclórica, unilateral e distorcida:

Num país cujos donos do poder descendem de escravizadores, a influência nefasta da escola se traduz não apenas na legitimação da situação de inferioridade dos negros, como também na permanente recriação e justificação de atitudes e comportamentos racistas. De outro lado, a inculcação de imagens estereotipadas induz a criança negra a inibir suas potencialidades, limitar suas aspirações profissionais e humanas e bloquear o pleno desenvolvimento da sua identidade racial. (ROSEMBERG, 2012, p. 33) ${ }^{2}$.

2 Manifesto resultado da "Marcha Zumbi dos Palmares contra o racismo, pela cidadania e a vida", realizado pelo Movimento Negro no dia 20 de novembro de 1995. Esse documento continha propostas e reinvindicações 
Nesta perspectiva, a luta do Movimento Negro é de grande valia e importância, pois resultou na criação de diversas políticas públicas que visam à promoção da igualdade racial. Entre elas, podemos citar, sobretudo no campo educacional, as Leis $\mathrm{n}^{\circ} 10.639 / 2003^{3}$ e $\mathrm{n}^{\circ} 11.645 / 2008^{4}$, que dizem respeito à obrigatoriedade do ensino da história e da cultura africana, afro-brasileira e indígena nos sistemas de educação básica, públicos e privados. A valorização das culturas infantis se constitui como um importante pilar para a identidade negra e no processo de formação identitária, uma vez que pode contribuir na desconstrução de representações que alienam a criança e a pessoa negra do seu próprio corpo e das suas raízes étnico-raciais.

A pesquisadora Petronilha B. da Silva ${ }^{5}$ intitula de "africanidades brasileiras [...] de um lado os modos de ser, viver, de organizar suas lutas, próprios dos negros brasileiros, e de outro lado, as marcas da cultura africana que, independente da origem étnica de cada brasileiro fazem parte do seu dia" (SILVA, 2000, p. 151). Nesse sentido, uma educação que favoreça essas africanidades é benéfica para a reconstrução histórica da resistência do povo negro no Brasil.

de combate ao racismo, à discriminação racial e às desigualdades sociais. $\mathrm{O}$ trecho citado expressa a necessidade de reforma e revisão dos currículos escolares, como uma das reinvindicações do Movimento Negro no campo da educação.

3 A Lei 10.639, de 9 de janeiro de 2003, estabelece a obrigatoriedade do ensino de "História e Cultura Afro-Brasileira" dentro das disciplinas que já fazem parte das grades curriculares do Ensino Fundamental e Médio com o objetivo de acentuar a participação da população negra na construção da identidade nacional.

4 A Lei 11.645, de 10 de março de 2008, altera a Lei 9394 de 20 de dezembro de 1996, uma vez que inclui nas Diretrizes e Bases da Educação Nacional, colocando no currículo oficial da rede de ensino a obrigatoriedade da temática "História e Cultura Afro-Brasileira e Indígena".

5 Professora titular de Ensino-Aprendizagem - Relações Étnico-raciais da Universidade Federal de São Carlos e pesquisadora do Núcleo de Estudos Afro-Brasileiros da mesma universidade. 
Quando a educação se abre para as africanidades proporciona um diálogo transformador e humanizador, permitindo a todos, e não só aos negros, a conquista de conhecimentos pautados na tradição e na memória, estabelecendo elementos em consonância com a cultura eurocêntrica presente na escola e busca corrigir as alterações "da cultura forjada pelas histórias oficiais, particularmente presentes [...] na história dos vencedores" (MONTEIRO, 2011, p. 124). Para este autor, a cultura das identidades e suas experiências históricas de lutas vividas são resgatadas pela memória e transmitida pela narração de história que se perpetua, fazendo "os diversos atores do presente (re) conhecerem-se, então, como interlocutores fundamentais por e para outros sujeitos históricos" (MONTEIRO, 2011, p. 124)

O professor e pesquisador Antônio Flávio Barbosa Moreira afirma que, uma vez presente no conteúdo dos currículos escolares, as africanidades possibilitam "desestabilizar a rigidez da lógica eurocêntrica, cristã, masculina, branca e heterossexual" (MOREIRA, 2001, p. 76), possibilitando um importante diálogo com novas formas de ver o mundo, uma vez que as produções da cultura negra proporcionam o aprofundamento perante as questões acerca da vida social, favorecendo olhares, perspectivas e valores que libertem ao invés de aprisionar. Sobre esta questão, é oportuno resgatar Costa (2008), para quem o estudo das africanidades possibilita novas formas de sociabilidade, desconstruindo valores que imobilizam, abrindo espaço para a construção de ações libertadoras.

Diante desse contexto, a promulgação das Leis $\mathrm{n}^{\circ}$ 10.639/03 e 11.645/08 marcou uma possibilidade de mudança no cenário educacional, visto que interrompeu com o abafo do histórico de desrespeito aos negros e índios, realocando-os para o território escolar. O debate propiciado por estas leis marca, desse modo, um novo ponto de vista para a educação, reivindicando um novo olhar sobre as relações étnico-raciais na escola, respeitando todas as suas variantes e complexidades. 
"Essa discussão traz em seu bojo tanto uma nova reflexão sobre a educação formal quanto novas possibilidades de se conceber o currículo. Entre elas, a invenção de uma escola capaz de representar e trabalhar a pluralidade cultural brasileira" (FERNANDES; SOUZA, 2016, p. 116). Trata-se de construir as ações pedagógicas sob uma perspectiva multicultural ${ }^{6}$, propagadora de uma educação que seja capaz de colaborar para uma construção positiva da identidade negra. A respeito disso, Souza (1983) destaca:

Ser negro é, além disto, tomar consciência do processo ideológico que, através de um discurso mítico acerca de si, engendra uma estrutura de descobrimento que o aprisiona numa imagem alienada, na qual se reconhece. Ser negro é tomar posse desta consciência e criar uma nova consciência que reassegure o respeito às diferenças e que reafirme uma dignidade alheia a qualquer nível de exploração. Assim, ser negro não é uma condição dada, a priori, é um vir a ser. Ser negro é tornar-se negro. (1983, p. 77)

Tais considerações nos levam a compreender que a construção (e reconstrução) do "ser negro" enfrenta um longo e intenso processo de conscientização e valorização da negritude, ao tempo que também passa pela construção política e sociocultural da sua identidade. Sobre essa identidade, Gomes (2003) afirma que se reconhecer nela "supõe, portanto, responder afirmativamente a uma interpretação e estabelecer um sentido de pertencimento a um grupo de referência". (2003, p. 171)

Após essa discussão, deve-se compreender que a escola

6 De acordo com Bento (2011), “o multiculturalismo aparece como princípio ético que orienta a ação de grupos culturalmente dominados. Falar de multiculturalismo é falar do jogo das diferenças cujas regras são definidas nas lutas sociais por atores que, por uma razão ou outra, experimentam o gosto amargo da discriminação e do preconceito das sociedades em que vivem". (2011, p. 29). 
precisa ser capacitada a fim de beneficiar as diferenças e o debate entre os sujeitos dos mais diversos grupos étnico-raciais, possibilitando ao aluno negro, desconstruir os estereótipos e preconceitos em relação à sua origem, conquistando e fortalecendo assim, um sentimento de pertença, que pode futuramente levá-lo a atuar em defesa dos valores e direitos do seu grupo étnico-racial. Por fim, consideramos que a escola não pode e nem deve ser um espaço de alienação da negritude e sim, um espaço que valorize a originalidade destruída pelo racismo. A escola pode, portanto, despertar na criança e no jovem negro um questionamento sobre o seu corpo, não de forma que o leve a tentativa de torná-lo branco, mas sim, de se fazer negro.

\section{CONSIDERAÇÕES FINAIS}

A escola se configura como um espaço privilegiado de formação identitária, uma vez que compreendemos a importância do ambiente escolar nos caminhos de construção de identidade da criança negra. Quando a instituição de ensino reconhece os saberes das diversas culturas ali presentes, ela reconhece também, todos(as) os(as) alunos(as) como sujeitos socioculturais que são frutos de suas experiências, sejam elas individuais ou coletivas. Do contrário, quando não se dá voz para esses saberes, o que se faz é reproduzir as práticas hegemônicas de exclusão, privilegiando a cultura eurocêntrica.

É preciso, sobretudo na escola, que é um dos principais espaços sociais que a criança conhece na vida (sendo a família, o primeiro), que haja um olhar dos educadores, da gestão pedagógica e de políticas sociais voltadas para essas questões para que essa temática possa, definitivamente, fazer parte da escola e da cultura da diversidade, já que é ali o primeiro ambiente em que a criança tem contato direto com o diferente. Não só com relação às crianças negras, mas também perante todas as diferenças (de modo geral), em busca de uma sociedade mais igualitária e inclusiva. Por fim, acreditamos na possibilidade de mudança 
da realidade opressiva a que está submetida a população afro-brasileira, mediante uma educação que proporcione a construção e a afirmação da identidade negra de forma resistente e positiva.

\section{REFERÊNCIAS}

BRAH, Avtar. Diferença, diversidade e diferenciação. Cadernos Pagu, n.26, jan-jun. 2006. Disponível em: <http://www.scielo.br/pdf/ cpa/n26/30396.pdf>. Acesso em 27 de junho de 2020.

COSTA, Sidney Alves. Militância do Movimento Negro na formação de professores em direitos humanos. Revista Segurança Urbana e Juventude. Vol. 1. n. 1, 2008. Disponível em: < $\underline{\text { https://periodicos. }}$ fclar.unesp.br/seguranca/article/view/1006/854>. Acesso em 27 de junho de 2020.

DA MATTA, Roberto. Digressão: a fábula das três raças ou o problema do racismo à Brasileira. In: DAMATTA, Roberto. Relativizando: uma introdução à antropologia social. 3. ed. Petrópolis: Vozes. 1983, p. $58-85$.

FANON, Frantz. Pele negra, máscaras brancas. Trad.: Renato Silveira. Salvador, Edufba, 2008.

FERNANDES, Viviane Barboza; SOUZA, Maria Cecília Cortez. Identidade Negra entre exclusão e liberdade. Revista do Instituto de Estudos Brasileiros. no 63. Abr. 2016 (p. 103-120).

GOMES, Nilma Lino. Cultura negra e educação. Revista Brasileira de Educação, n. 23, maio-ago. 2003. Disponível em: < $\underline{\text { http://www. }}$ scielo.br/pdf/rbedu/n23/n23a05.pdf $>$ Acesso em 27 de junho de 2020.

GOMES, Nilma Lino. Educação, identidade negra e formação de professores/as: um olhar sobre o corpo negro e o cabelo crespo. Educação e Pesquisa. Vol. 29. n. 1. Jan-jun. 2003. Disponível em: $<$ http://www.scielo.br/pdf/ep/v29n1/a12v29n1.pdf $>$. Acesso em 27 de junho de 2020.

HALL, Stuart. Da diáspora: Identidade e mediações culturais. Tradução: Adelaine La Guardiã Resende. Belo Horizonte/Brasília. Editora UFMG. Representação da UNESCO no Brasil. 2003. 
JESUS, Ilma Fátima. O pensamento do MNU - Movimento Negro Unificado. In: SILVA, Petronilha Beatriz G-onçalves e BARBOSA, Lucia Maria de Assunção (orgs.). O pensamento negro em educação no Brasil: expressões do movimento negro. São Carlos Editora da UFSCar, 1997.

LOURO, Guacira Lopes (org.). Pedagogia da sexualidade. O corpo educado: pedagogias da sexualidade. Belo Horizonte. Autêntica, 2009.

MELUCCI, Alberto. O jogo do Eu: a mudança de si em uma sociedade global. São Leopoldo, Editora Unisinos. 2004.

MONTEIRO, Aloisio Jorge de Jesus. Fronteira, cultura e exclusão: debates do nosso tempo. n. 31, jan-jun, 2011. Disponível em: $<\underline{\text { https:// }}$ site.ucdb.br/public/downloads/9005-edicao-31-jan-jun-2011.pdf $>$. Acesso em 27 de junho de 2020.

MOREIRA, Antônio Flavio Barbosa. A recente produção científica sobre currículo e multiculturalismo no Brasil. 1995-2000: Avanços, desafios e tensões. Revista Brasileira de Educação. n. 18. Set-dez. 2001. Disponível em: < $\underline{\text { http://www.scielo.br/pdf/rbedu/n18/n18a07> }}$ Acesso em 27 de junho de 2020.

MUNANGA, Kabengele. Negritude e identidade negra ou afrodescendente: um racismo ao avesso? Revista da ABPN, vol. 4, n. 8, 2012, p.9.

NOGUEIRA, Izildinha Beatriz. Significações do Corpo Negro. Tese de doutorado. São Paulo: Universidade de São Paulo, 1998.

NOGUEIRA, Oracy. Preconceito racial de marca e preconceito racial de origem: sugestão de um quadro de referência para a interpretação do material sobre relações raciais no Brasil. Tempo Social, vol. 19, n. 1, p. 287-308. 2007. Disponível em: < http://www.scielo.br/pdf/ts/ v19n1/a15v19n1.pdf $>$. Acesso em 27 de junho de 2020.

PARÉ, Marilene Leal. Auto-imagem e auto-estima na criança negra: um olhar sobre o seu desempenho escolar. Dissertação de mestrado. Porto Alegre: Pontifícia universidade Católica do Rio Grande do Sul, 2000.

ROSEMBERG, Fúlvia. A criança pequena e o direito à creche no contexto dos debates sobre infância e relações raciais. In: BENTO, 
Maria Aparecida Silva (org.). Educação Infantil, igualdade racial e diversidade infantil: aspectos políticos, jurídicos e conceituais. São Paulo: Centro de Estudos das Relações de Trabalho e Desigualdades (CEERT). 2012, p. 33.

SCHUCMAN, Lia Vainer. Entre o "encardido", o "branco" e o "branquíssimo": raça, hierarquia e poder na construção da branquitude paulistana. Tese de doutorado. São Paulo: Universidade de São Paulo, 2012.

SILVA, Ana Célia. A representação social do negro no livro didático: o que mudou? Por que mudou? Salvador. Edufba. 2011.

SILVA, Petronilha Beatriz Gonçalves. Aprendizagem e ensino das africanidades brasileiras. In: MUNANGA, Kabengele (org.). Superando o racismo na escola. Brasília, BMEC/ Secretaria de educação Fundamental/ MEC/ UNESCO, 2000.

SOUZA, Fernanda Morais. Revirando malas: entre histórias de bonecas e crianças. Porto Alegre, 2010.

SOUZA, Neusa Santos. Tornar-se negro. Rio de Janeiro. Graal. 1983.

\section{SOBRE AS AUTORAS}

Carolina Zolin Carneiro. Graduada em Comunicação Social (2012-2015) e em Pedagogia (2016-2019), ambas pela Universidade Metodista de São Paulo. Atua na área da educação desde 2013, com foco na Educação Infantil. Professora da rede privada do município de São Paulo. E-mail para contato: zocazolin58@gmail.com

Maria José de Oliveira Russo. Graduada em Pedagogia, Mestre e Doutora em Educação. Coordenadora e docente do curso de Pedagogia presencial da Universidade Metodista de São Paulo. E-mail para contato: maria.russo@metodista.br 